\title{
HOW-TO-INFLUENCE-BEHAVIOUR MODEL AND SPEED CHOICE
}

\author{
Matúš Šucha ${ }^{1}$ \\ ${ }^{1}$ Department of Psychology, Faculty of Arts, Palacky University, Krizkovskeho 10, 771 80, Olomouc, Czech \\ Republic
}

Received 27 March 2017; accepted 3 May 2017

\begin{abstract}
This article presents the How-to-influence-behaviour model, the purpose of which is to describe situation-specific factors that influence the behaviour of road users, drivers in particular. Behaviour is considered to be the result of the action of human-specific and situation-specific factors; it cannot be influenced directly, but through interventions at the level of the given factors. The model focuses on to what extent situation-specific factors are influenced by interventions at the societal level. Indeed, it is society rather than a human being as an individual entity that is responsible for the implementation and effectiveness of such interventions. Relationships with other relevant approaches, such as the 3 E's (Enforcement, Engineering, and Education) and hierarchic models of human behaviour in traffic (e.g. the Gadget model) are pointed out. The application of the model is illustrated through the issue of the choice of a safe driving speed. The levels of the process of a driver's choice of speed (the levels of knowledge, experience, values, and attitudes and the metalevel) and the areas of the interventions according to the model (traffic rules and law enforcement, vehicle design, traffic infrastructure, and culture and norms) are defined. Available evidence concerning interventions and their effects on traffic safety (effectiveness) leads to the conclusion that the domains of traffic rules and law enforcement are represented to a significant extent, especially at Levels 1 and 2 of drivers' decision making (knowledge and experience). On the other hand, very little information is available about interventions aimed at Levels 3 and 4 of drivers' decision making (values, attitudes, and the metalevel) and the domain of traffic culture.
\end{abstract}

Keywords: How-to-influence-behaviour model, traffic safety, behaviour, speed choice.

\section{Introduction}

Speeding is a high-risk road use behaviour (e.g. WHO, 2015). The legal definitions of speeding include exceeding the posted speed limit or driving too fast for the current conditions. Speeding becomes aggressive driving when a vehicle's speed substantially exceeds the prevailing travel speeds of other vehicles (Goodwin et al., 2013). Speeding is common. About three-quarters of all the drivers in NHTSA's 2002 national survey reported that they exceeded the posted speed limit on various types of roads. Specifically, $78 \%$ of the drivers reported speeding on interstates, $83 \%$ on non-interstate multilane roads, $78 \%$ on two-lane roads, and $73 \%$ on city streets during the past month. Onequarter to one-third of the drivers reported speeding on the various types of roads on the day of the interview (NHTSA, 2004).

A reduction in the average driving speed dramatically reduces the traffic accident rate

\footnotetext{
${ }^{1}$ Corresponding author: matus.sucha@upol.cz
} 
and the number of road use-related injuries and fatalities (Nilsson, 2004). Driving is a self-paced task, i.e. the level of speed is the driver's choice. Hence, if we wish to enhance safety (and reduce the number of accidents, injuries, and fatalities), we need to ensure that drivers opt for a lower, or suitable, travel speed. It is therefore necessary to influence their behaviour.

From the perspective of psychology, any behaviour is the effect (visible) of the action of multiple factors, which can generally be divided into factors that influence the driver from within and those that do so from without. Psychology studies especially the factors that shape behaviour and exert an influence on the driver from within. While innate and invariable to a certain degree, these factors can also be shaped, although in the long term and by means of intensive psychological interventions (e.g. rehabilitation programmes) or training (e.g. driving schools). In terms of road safety practice, however, the key factors are those that act on the driver from without, as it is easier, faster, and more effective to influence these. Moreover, these interventions are targeted at the driver population as a whole, or specified groups of the driver population, as applicable, rather than at individuals.

Overall, drivers' choice of travel speed is the result of the action of multiple factors. If we wish to influence such behaviour, we need to work to influence these factors rather than the behaviour itself (which is viewed as a consequence). The internal factors (in terms of traffic safety) can be influenced mainly by long-term and, in particular, individualised interventions. These include education and training (driving school) or other psychological and psychotherapeutic interventions (such as rehabilitation programmes for drivers with repeated speeding offences). External factors are those that act on drivers' behaviour directly from without. They include traffic rules and the ways in which they are enforced, vehicle design, the traffic infrastructure, and the (traffic) culture of the location or country under consideration.

\section{How-to-Influence-Behaviour Model - Introduction}

The How-to-influence-behaviour model describes the options for influencing human behaviour in traffic. The model is based on the assumption that human behaviour is a consequence of people's effort to satisfy their needs. Behaviour is thus shaped by human needs, preferences, and motives. Nevertheless, the form of behaviour a person engages in is also influenced by additional factors that may be humanspecific (i.e. internal, such as individual personality structure, values, and norms) or situation-specific (i.e. external, such as the type of road or the power of their car). The most common interventions aimed at influencing people's road safety behaviour at the level of human-specific factors include education (especially driving schools), training (such as that focused on specific driving skills), assessment of psychological fitness to drive (education, promotion of better insight, and selection for further therapeutic interventions), and rehabilitation programmes (therapeutic and educational interventions targeted at risky drivers). The purpose of these interventions is to educate and train drivers (to provide them with information and enhance their skills), as well as improving their insight and raising their awareness and sense of responsibility (safety). Interventions are applied at the individual level, either generally (e.g. 
through driving schools) or selectively (e.g. training projects for professional drivers or rehabilitation programmes). The effectiveness of the interventions relies on the assumption that people will opt for safe behaviour if they are provided with relevant information, are taught to use it in practice (skills), and attain awareness and insight (can make use of the knowledge they have acquired in contributing to better safety). One limitation is that the choice of behaviour remains the responsibility of an individual. Therefore, the resulting behaviour will always pose a certain level of risk (as, by nature, a human being makes mistakes and is irrational and imperfect). In terms of traffic safety, this limitation is critical to the extent that the failure of an individual may have a harsh impact on society. For this reason, it was found the situation-specific interventions (depicted in the model inside the "Interface" rectangle) more suitable. In particular, following Diamond model (Chaloupka-Risser, Risser \& Zuzan, 2011; Risser, 2004), they are the interventions delivered at the following four levels:

1. Traffic regulations and effective enforcement;

2. Means of transport and their ergonomy;

3. Traffic infrastructure;

4. Traffic culture.

There is a vast empirical evidence (e.g. Elliott \& Broughton, 2004; Evans, 2004) that situation-specific interventions lead to reductions in serious injuries and fatalities and have positive effect on traffic safety, concretely, in the respect of How-toinfluence-behaviour model and its parts, traffic regulations and effective enforcement (Bjørnskau \& Elvik, 1992), means of transport and their ergonomy (Christensen \& Elvik, 2007), traffic infrastructure (Dewar et al., 2001) and traffic culture (Ward et al., 2010). On the other hand, positive effects and public benefits in the terms of traffic safety of human-specific interventions are unclear (e.g. Ker et al., 2005; Christie et al., 2007).

Situation-specific interventions are implemented at the societal rather than individual level. It is therefore society that is responsible for their implementation and effectiveness, not a person as an individual. In figurative terms, one might say that situation-specific interventions provide a road user with a framework within which they can subsequently choose their (more or less risky) behaviour. However, this framework must be specific to the extent that no individually chosen behaviour leads to serious social harm (such as death or severe injury). This principle is in line with Vision Zero, a generally accepted approach to road safety: "The system designers are invariably ultimately responsible for the design, management and use of the road transport system; thus, they are jointly responsible for the level of safety of the whole system. The road users are obliged to abide by the rules that the system designers decide on for the use of the road transport system. If the road users fail to abide by the rules - for example due to lack of knowledge, acceptance or ability - or if personal injuries occur, the system designers must take additional measures to prevent people from dying or being seriously injured" (Fahlquist, 2006, p. 1113, quoting the Swedish law).

The key role of situation-specific interventions in road safety was also declared by the 2016 Dutch Presidency of the Council of the European Union. The road safety priorities for the EU in 2016 include the full use of the safety potential of automated 
driving and the revision of vehicle safety legislation that has the potential to lay the foundations for automated driving and infrastructure safety measures (ETSC, 2015).

The areas of interventions are depicted sequentially in the model from left to right, starting with those that are the quickest and cheapest to implement and have a fast impact, and progressing towards those that are time-consuming, expensive, and have an impact that takes decades to set in.

The model is conceived as a cycle (Figure 1 shows the sequence of one cycle); the arrow from "behaviour of road users" back to "needs, preferences and motives of road users" represents the fact that despite it being the result of the preceding steps, the resulting behaviour of road users has a knockon effect on human needs, preferences, and motives. This gives rise to a cycle where the initial (starting) point is determined by the result. Rather than a simple cycle (circle), this scheme involves a spiral (in the sense of the philosophy of G. W. F. Hegel, e.g. Hegel, 2010), where each additional repetition of the cycle is the repetition of the same principle on a qualitatively different (higher) level.

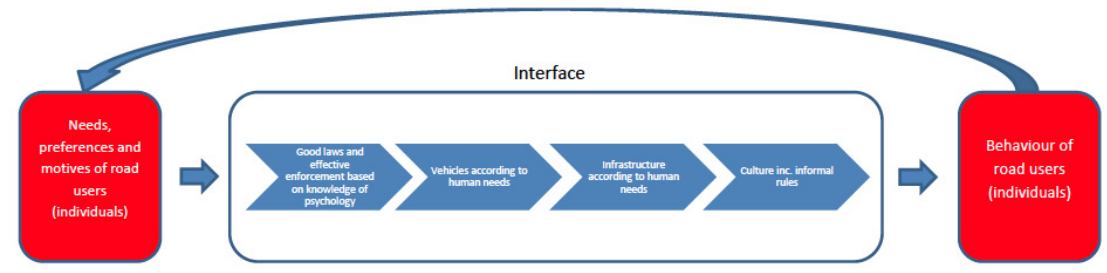

Fig. 1.

How-to-Influence-Behaviour Model

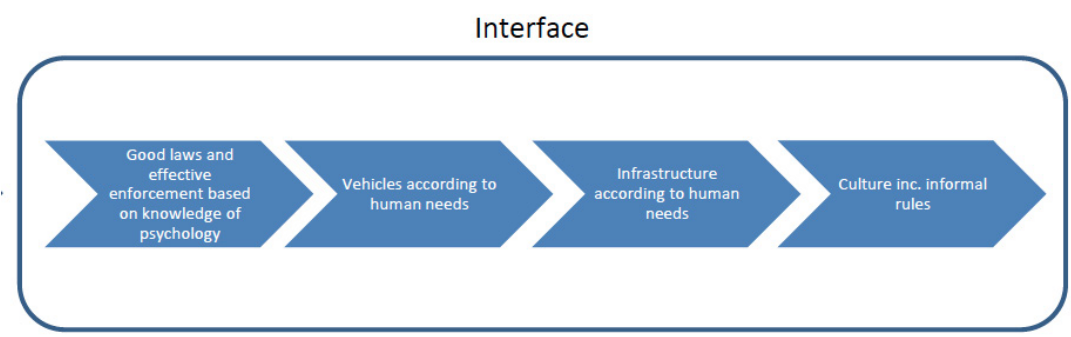

Fig. 2.

How-to-Influence-Behaviour Model - the Interface Segment in Close-Up 


\section{Other Related Models}

As road user behaviour is not driven only by rational considerations, psychologists have dealt with this by using different models of road user behaviour simultaneously. The various approaches to traffic psychology, with respect to road user behaviour, can be summarised as those that are oriented towards input-output, or behaviour, and those that are motivation-oriented. In the second place, it can be distinguished between taxonomic and functional models which represent systems, the components of which respectively do and do not interact dynamically (Fuller, 2005). Taxonomic models of driver behaviour are exemplified by trait models (e.g. Conger et al., 1959) and by task analysis (e.g. McKnight \& Adams, 1970). Functional models are represented by compensation models (e.g. the risk-speed compensation model (Taylor, 1994), or the risk homeostasis theory (Wilde, 1982)), the risk threshold theory (Klebelsberg, 1971), or the threat avoidance model (Fuller, 1984).

As regards models which conceptualise factors that influence road use behaviour, hierarchic models are the most recent and common. Having a relatively long tradition in traffic psychology (Michon, 1989; Rasmussen, 1980; Summala, 1985), these models focus mainly on performance factors (analysis of driving in terms of the individual procedures that a driver must perform), but they can also be applied to personality and motivational factors. Building upon all the above models, (Hatakka et al., 2002) devised the so-called Gadget model, which explicitly incorporates all the variables of interest (performance characteristics, personality characteristics, and motivation factors).
This model must be viewed in the context of interaction between drivers' needs, preferences, and objectives, their specific behaviour (conducive to the given objective), and the feedback on this behaviour. The model is based on the assumption that the higher levels (i.e. motivational factors) influence and control behaviour at the lower levels (i.e. skills and abilities).

In line with the Gadget model, the How-toinfluence-behaviour model treats the chosen behaviour as the effect of multiple factors that exert an influence on a person. Unlike the Gadget model, however, it focuses on situational factors rather than on humanspecific factors and their hierarchisation. In this respect, the How-to-influencebehaviour model and Gadget models can be seen as complementing each other.

In terms of the approach to traffic safety as proposed by the 3 E's - Education, Engineering, and Enforcement - model, the How-to-influence-behaviour model is particularly concerned with Engineering and Enforcement, areas which are more specific to situation-oriented factors that influence human behaviour. The Education area focuses more on human-specific factors that influence the actual road use behaviour. As for empirical evidence of the positive effect of interventions in the individual areas of the $3 \mathrm{E}$ 's on public health, no positive effect on public health in the Education area has been demonstrated (e.g. Mayhew \& Simpson, 2002). Conversely, however, there is consistent evidence that interventions implemented in the Engineering and Enforcement areas have a positive effect on public health in terms of traffic safety (Tay, 2005). 


\section{Options for Influencing Behaviour - Speed Choice}

This section deals with the application of the model to the options for influencing drivers' behaviour in relation to their choice of speed. Speeding is one of the major causes of trafficrelated accidents, injuries, and fatalities (e.g. ERSO, 2006). From a certain perspective, speed can be regarded as a background, or an intervening factor, which has an impact on all the other risky behaviours of road users: the higher the speed, the less time for a correct reaction and the higher the risk of an accident. In addition, the choice of speed is exclusively at the driver's discretion (assuming that we disregard the maximum speed that a car can reach, which is, however, much higher than the legal or safe speed in the vast majority of cases).

The process of speed choice can be divided into several levels. Each decision-making level is influenced by different factors (both human- and situation-specific) and requires different forms of intervention to produce an effect on the driver's eventual decision and behaviour. The levels are as follows:

1. Knowledge level: a driver must know which speed is legal and which is safe at a given moment;

2. Experience level: a driver must pay attention to the choice of speed or select appropriate speed intuitively;

3. Values and attitudes level: a driver must want to choose a safe speed;

4. Metalevel: a driver must understand the societal implications of speed choice; e.g. even a subtle increase in the risk of an accident when an individual opts for an inappropriate speed (negligible at the individual level) is critical from the perspective of society as a whole (when each of the enormous number of drivers contributes to a slight increase in the risk, it can have a major negative impact on traffic safety at the societal level).

As indicated above, the How-to-influencebehaviour model is applied to interventions which have the potential to influence human behaviour in traffic and are situationspecific. Therefore, it will be discussed further the options for interventions and ways of influencing the choice of behaviour according to the levels outlined above in terms of situation-specific factors and related interventions only.

Table 1 proposes areas of interventions in terms of the choice of safe speed, broken down in the matrix according to the Howto-influence-behaviour model (areas: traffic regulations and law enforcement, vehicle design, traffic infrastructure, culture and norms) and drivers' decision-making areas (i.e. the knowledge, experience, values and attitudes levels, and the metalevel). The main purpose of this distinction is to highlight the significance of the several levels of human decision making and the fact that each level requires different forms of intervention. In line with the How-to-influence-behaviour model, we propose four possible areas of intervention (situation-specific factors), while pointing out that interventions must be applied consistently to all the model domains and to all the human decision-making levels to ensure that the entire process is successful, i.e. that true changes in people's road use behaviour are achieved. 
Table 1

Speed Choice Interventions According to the How-to-Influence-Behaviour Model and Drivers' DecisionMaking Levels

\begin{tabular}{|c|c|c|c|c|}
\hline & $\begin{array}{l}\text { Traffic rules and } \\
\text { law enforcement }\end{array}$ & Vehicle design & $\begin{array}{c}\text { Traffic } \\
\text { infrastructure }\end{array}$ & Culture and norms \\
\hline 1. Knowledge level & $\begin{array}{l}\text { Clear-cut and } \\
\text { simple regulations } \\
\text { concerning speed } \\
\text { limits. }\end{array}$ & $\begin{array}{l}\text { On-board ITS } \\
\text { alerting the driver } \\
\text { about the speed limit } \\
\text { at a given location. }\end{array}$ & $\begin{array}{l}\text { Road signalling } \\
\text { explicitly stating the } \\
\text { speed limit at a given } \\
\text { location. }\end{array}$ & $\begin{array}{l}\text { Unwritten norms } \\
\text { which conform } \\
\text { with a formal norm } \\
\text { (regulations). Road } \\
\text { safety campaigns } \\
\text { focused on } \\
\text { awareness-raising. }\end{array}$ \\
\hline 2. Experience level & $\begin{array}{l}\text { Effective law } \\
\text { enforcement so that } \\
\text { any benefit from } \\
\text { the violation of } \\
\text { regulations is not } \\
\text { enough to offset } \\
\text { the probability } \\
\text { and severity of } \\
\text { punishment } \\
\text { (stationary and } \\
\text { manual speed } \\
\text { enforcement and } \\
\text { speed cameras). }\end{array}$ & $\begin{array}{l}\text { On-board ITS } \\
\text { actively/ invasively } \\
\text { intervenes in the } \\
\text { choice of speed and } \\
\text { provides the driver } \\
\text { with feedback - } \\
\text { regulated automobile } \\
\text { top speed. }\end{array}$ & $\begin{array}{l}\text { Self-explaining } \\
\text { infrastructure } \\
\text { (intuitively } \\
\text { prompting the driver } \\
\text { about the safe and } \\
\text { legal speed at a given } \\
\text { location) - speed- } \\
\text { reducing devices } \\
\text { such as speed humps, } \\
\text { raised junctions, } \\
\text { rumble strips, and } \\
\text { speed zones. }\end{array}$ & $\begin{array}{l}\text { Environment which } \\
\text { does not accept } \\
\text { cases of the breach } \\
\text { of regulations } \\
\text { (speeding) - negative } \\
\text { feedback from } \\
\text { other drivers in } \\
\text { response to one's } \\
\text { speeding. Road safety } \\
\text { campaigns focused } \\
\text { on awareness- raising } \\
\text { and behavioural } \\
\text { change. }\end{array}$ \\
\hline $\begin{array}{l}\text { 3. Values and } \\
\text { Attitudes level }\end{array}$ & $\begin{array}{l}\text { Traffic rules and } \\
\text { law enforcement } \\
\text { practices which the } \\
\text { driver finds logical, } \\
\text { appropriate, safe, and } \\
\text { fair. They understand } \\
\text { it and identify with } \\
\text { them. }\end{array}$ & $\begin{array}{l}\text { Vehicles designed } \\
\text { in such a way as to } \\
\text { highlight benefits } \\
\text { other than speed - } \\
\text { e.g. safety, economy, } \\
\text { environmental } \\
\text { friendliness, and } \\
\text { comfort. }\end{array}$ & $\begin{array}{l}\text { Infrastructure which } \\
\text { offers the chance to } \\
\text { reach the destination } \\
\text { comfortably, quickly, } \\
\text { and safely at a } \\
\text { reasonable speed } \\
\text { (not exceeding the } \\
\text { speed limit/safe). }\end{array}$ & $\begin{array}{l}\text { The influence of } \\
\text { the family, friends, } \\
\text { the community, } \\
\text { and reference role } \\
\text { models (groups). } \\
\text { Responsibility for } \\
\text { one's own life and } \\
\text { health. }\end{array}$ \\
\hline 4. Metalevel & $\begin{array}{l}\text { Traffic rules and } \\
\text { law enforcement } \\
\text { practices which } \\
\text { lead to the general } \\
\text { well-being of society } \\
\text { (higher safety) and } \\
\text { which the driver } \\
\text { understands and } \\
\text { identifies with, } \\
\text { despite the safety } \\
\text { impact at the } \\
\text { individual level being } \\
\text { negligible. }\end{array}$ & $\begin{array}{l}\text { Vehicles designed } \\
\text { in such a way as } \\
\text { to contribute } \\
\text { to safe, fluent, } \\
\text { and comfortable } \\
\text { transportation in } \\
\text { partnership with } \\
\text { other vehicles and } \\
\text { infrastructural } \\
\text { elements when a safe } \\
\text { speed is chosen. }\end{array}$ & $\begin{array}{l}\text { Infrastructure } \\
\text { designed in such a } \\
\text { way as to benefit all } \\
\text { the parties involved } \\
\text { (in terms of better } \\
\text { comfort, safety, and } \\
\text { journey time) in } \\
\text { cooperation with the } \\
\text { driver, the vehicle, } \\
\text { and other drivers } \\
\text { when a reasonable/ } \\
\text { safe speed is chosen. }\end{array}$ & $\begin{array}{l}\text { Influence of the } \\
\text { entire society and its } \\
\text { values. Responsibility } \\
\text { for the community } \\
\text { one is part of and } \\
\text { for others' health } \\
\text { and lives - at both } \\
\text { the individual and } \\
\text { societal levels. }\end{array}$ \\
\hline
\end{tabular}

(Source: Author)

Available documents (e.g. Countermeasures that work: A highway safety countermeasures guide for State Highway Safety Offices, Goodwin et al., 2013; TRB Special report
254 Managing Speed, TRB, 1998; and The handbook of road safety measures, Elvik \& Vaa, 2004) are particularly concerned with the assessment of the effectiveness 
of the individual interventions in the area of traffic rules and law enforcement (e.g. speed limits, types of sanctions/penalties, and automatic surveillance - especially camera systems). The main emphasis is placed on the first decision-making level (Knowledge), but sometimes also on the second level (Experience), particularly through nationwide road safety campaigns. In terms of the matrix (Table 1), it could be concluded that the more we move towards the upper left-hand segment, the more information about the interventions and their effectiveness we find, while the more we move towards the lower right-hand sections of the table, the less relevant information is available.

\section{Conclusions}

The Human-behaviour-in-traffic model is aimed at describing situational factors which have an influence on people's trafficrelated decision making. Human behaviour is regarded as a consequence of multiple processes which are affected by factors that can be divided into human-specific and situation-specific ones. It means that behaviour cannot be influenced directly. Instead, the factors that affect people's decision making and their final choice of behaviour must be worked upon. Human behaviour is primarily determined by individual needs, desires, and preferences. Nevertheless, the behaviour which a person chooses (to satisfy their needs) is determined by a number of additional factors. In the model, these are depicted in blue as "Interface" (see Figure 2). In terms of trafficrelated issues, we focus on the description of situation-specific factors (the model does not account for human-specific factors). Unlike needs and the human behaviour that reflects them, these factors can be influenced at the societal level, and society is also responsible for the assurance of conditions (factors) which lead to safe traffic.

In terms of options for influencing people's decision making when choosing their speed, the different levels at which this decision making occurs (knowledge, experience, values and attitudes, and the metalevel) need to be taken into account. These levels differ in a qualitative sense and each requires different interventions. If we want to achieve an effective result as well - i.e. a change in drivers' speed choice behaviour towards higher safety - it is vital to work upon all the decision-making levels and all the areas simultaneously and consistently (model - traffic rules and effective enforcement thereof, means of transport and their ergonomic characteristics, traffic infrastructure, and traffic culture).

The interventions, or situation-specific factors, which need to be affected with respect to changes in drivers' speed choice behaviour are proposed in Table 1, where they are structured according to the decisionmaking levels and areas of application (model). The resulting intervention matrix combines both of these concepts. A literature review suggested that the interventions that are relatively well-known, commonly implemented, and evaluated (evaluation of effectiveness and cost-benefit analyses) are especially those that target lower decisionmaking levels (particularly the knowledge and experience levels) and those addressing the domains of the enforcement of laws and traffic regulations, traffic infrastructure, and means of transport. Specifically, these concern the determination of speed limits, traffic surveillance (speed measurement and sanctions for speeding), the issue of fines and other penalties, and traffic-calming 
measures in urban areas (such as speed zones and speed humps) or on-board ITSs alerting drivers about the speed limit or driving in excess of it.

Interventions aimed at higher decisionmaking levels - i.e. the values and attitudes domain and the metalevel - and interventions targeting the domain of culture, and traffic culture, in particular, are implemented to a much lesser degree (or not at all), and evidence of their effectiveness (i.e. their relationship with traffic safety, expressed especially by the number and severity of road accidents and injuries and the number of fatalities) is sparse or non-existent.

As pointed out previously, for the final effect on changes in behaviour to be effective, i.e. to influence drivers' speed choice behaviour towards them opting for a safe alternative, it is necessary to work upon all the levels and all the domains continually, simultaneously, and consistently. As regards practical implications, therefore, we recommend that interventions targeting higher decision-making levels and the traffic culture domain should be developed, implemented, and evaluated for effectiveness. Intervention at the values and attitudes level should focus on traffic regulations and law enforcement in such a way as to ensure that drivers understand the rules and find them logical, appropriate, safe, and fair. This will help drivers identify with and observe the rules. Vehicles should be designed in such a way as to provide drivers with intuitive guidance towards safe and comfortable rather than fast and aggressive driving. Interventions addressing the domain of traffic infrastructure should offer a comfortable, quick, and safe way of reaching the destination at a reasonable speed. There should be an emphasis on responsibility for one's own and others' life and health, fostered by interventions making use of the influence of the family, friends, the community, and reference role models (groups). The metalevel interventions concerning traffic regulations and law enforcement should aspire to general societal well-being (greater safety) and drivers should understand and identify with them. To a certain degree, this involves the extension of interventions beyond the values and attitudes level, with the interventions at the metalevel underlying positive effects on society in its entirety, even if - as it may be such behaviour yields no benefit at the level of the individual driver. In terms of vehicle design and infrastructure, this concerns interventions which ensure that vehicles are designed in such a way as to contribute to safe, fluent, and comfortable traffic for all (i.e. in terms of better comfort, safety, and journey time), in partnership with other vehicles and infrastructure and when a safe speed is chosen. Intervention at the culture level must aim at society as a whole, societal values, and individuals' responsibility for the community they are part of and for the lives and health of others.

\section{Acknowledgement}

This research was funded by research grant of Ministry of Education of Czech republic, project IGA FF_2017_021 "Psychology research in the selected fields of pedagogical and clinical psychology.

\section{References}

Bjørnskau, T.; Elvik, R. 1992. Can road traffic law enforcement permanently reduce the number of accidents?, Accident Analysis \& Prevention 24(5): 507-520. 
Chaloupka-Risser, Ch.; Risser, R.; Zuzan W.D. 2011. Verkehrspsychologie. Grundlagen und Anwendungen [Traffic psychology: Theory and practice]. FacultasVerlag, Wien. 145 p.

Christensen, P.; Elvik, R., 2007. Effects on accidents of periodic motor vehicle inspection in Norway, Accident Analysis \& Prevention 39(1): 47-52.

Christie, N.; Cairns, S.; Towner, E.; Ward, H. 2007. How exposure information can enhance our understanding of child traffic "death leagues", Injury prevention 13(2): 125-129.

Conger, J. J.; Gaskill, H. S.; Glad, D. D.; Hassel, L.; Rainey, R. V.; Sawrey, W. L.; Turrell, E. S. 1959. Psychological and psycho physiological factors in motor vehicle accidents: Follow-up study, Journal of the American Medical Association 169(14): 1581-1587.

Dewar, R. E.; Olson, P. L.; Alexander, G. J. 2001. Perception and information processing, in: Dewar, $\mathrm{R}$. E., Olson, P. L. (Eds.), Human Factors in Traffic Safety. Lawyers and Judges Publishing, Co. Int., Tucson, AZ. 223 p.

Elliott, M.; Broughton, J. 2004. How methods and levels of police affect road casualty rates. TRL Report PR SE/924/04. Transport Research Laboratory, Crowthorne, England. $43 \mathrm{p}$.

Elvik, R.; Vaa, T. (Eds.). 2004. The Handbook of Road Safety Measures. Pergamon, Amsterdam. 564 p.

ETSC, 2015. 9th Road Safety Performance Index Report. Available at http://etsc.eu/9th-annual-road-safetyperformance-index-pin-report/. Accessed March 10, 2016.

European Road Safety Observatory, 2006. Speeding. Available at: www.erso.eu. Accessed January 20, 2007.

Fahlquist, J. N. 2006. Responsibility ascriptions and Vision Zero, Accident Analysis \& Prevention 37: 601-603.
Evans, L. 2004. Traffic safety. Science Serving Society, MI, USA. 355-356p.

Fuller, R. 1984. A conceptualization of driving behaviour as threat avoidance, Ergonomics 27(11): 1139-1155.

Fuller, R. 2005. Towards a general theory of driver behaviour, Accident Analysis \& Prevention 37: 461-472.

Goodwin, A.; Kirley, B.; Sandt, L.; Hall, W.; Thomas, L.; O'Brien, N.; Summerlin, D. 2013. Countermeasures that work: A highway safety countermeasures guide for State Highway Safety Offices, 7th edition. (Report No. DOT HS 811 727). National Highway Traffic Safety Administration, Washington, DC. 233-234p.

Hatakka, M.; Keskinen, E.; Gregersen, N. P.; Glad, A.; Hernetkoski, K. 2002. From control of the vehicle to personal self-control; broadening the perspectives to driver education, Transportation Research Part F 5(3): 201-215.

Hegel, G. W. F. 2010. Wissenschaft der Logik [Doctrine of Being]. Science of Logic, tr. George di Giovanni. Cambridge University Press, UK. 210-212 p.

Keskinen, E. 1996. Why do young drivers have more accidents? Junge Fahrer und Fahrerinnen. Referate der Ersten Interdiziplinären Fachkonferenz, December 12-14, 1994, Köln, Germany. In: Berichte der Bundesanstalt für Strassenwesen. Mensch und Sicherheit, Heft M 52.

Ker, K.; Roberts, I.; Collier, T.; Beyer, F.; Bunn, F.; Frost, C. 2005. Post-licence driver education for the prevention of road traffic crashes: a systematic review of randomised controlled trials, Accident Analysis \& Prevention 37(2): 305-313.

Klebelsberg, D. 1971. Subjektive und objektive Sicherheit im Strassenverkehr als Aufgabe für die Verkehrssicherheitsarbeit. Schriftenreihe der deutschen Verkehrswacht [Subjective and objective safety in the field of traffic psychology and traffic safety in general in German context], 51: 3-12. 
Mayhew, D. R; Simpson, H. M. 2002. The safety value of driver education and training, Injury Prevention, 8(suppl 2): ii3-ii8.

McKnight, A. J.; Adams, B. B. 1970. Driver Education Task Analysis. Volume II: Task Analysis Methods. Final Report. Available at: http://files.eric.ed.gov/fulltext/ ED075624.pdf. Accessed March 9 ${ }^{\text {th }}, 2016.49$ p.

Michon, J. A. 1989. Explanatory Pitfalls and Rule-Based Driver Models, Accident Analysis \& Prevention 21(4): 341353.

NHTSA, 2004. Safe Routes to School: Practice and Promise. Author, Washington, DC. Available at www. nhtsa.dot.gov/people/injury/pedbimot/bike/SafeRoutes-2004/. Accessed March 10 ${ }^{\text {th }}, 2016$.

Nilsson, G. 2004. Traffic safety dimensions and the power model to describe the effect of speed on safety. PhD thesis, Lund University, Norway. 131-132 p.

Rasmussen, J. 1980. What can be learned from human error reports, in Duncan, K., Grunenberg, M. \& Wallis, D. (Eds.), Changes in Working Life. Wiley, London. 55-56 p.

Risser R. 2004. Philosophy of Traffic Calming, The Asian Journal, Journal of Transport and Infrastructure 11(1): 1-9.

Summala, H. 1985. Modeling driver behavior: A Pessimistic Prediction?, in: Evans, L. \& Schwing, R., (Eds.), Human Behavior and Traffic Safety. Plenum Press, New York.
Tay, R. 2005. Drink driving enforcement and publicity campaigns: are the policy recommendations sensitive to model specification? Accident Analysis \& Prevention 37(2): 259-266.

Taylor, D. H. 1994. Drivers' galvanic skin response and the risk of accident, Ergonomics 7: 439-451.

TRB, 1998. Managing Speed. Review of Current Practice for Setting and Enforcing Speed Limits. Special report 254. Author, Washington, DC. 34-45 p.

WHO, 2015. Global status report on road safety 2015. Author, Geneva. Available at http://www.who.int/ violence_injury_prevention/en/. Accessed March $9^{\text {th }}, 2016$.

Ward, N. J.; Linkenbach, J.; Keller, S. N.; Otto, J. 2010. White paper on traffic safety culture. the series: White Papers for "Toward zero deaths: a national strategy for highway safety"-White Paper, (2). Available at http:// www.westerntransportationinstitute.org/documents/ reports/4w3048_final_report.pdf. Accessed March $10^{\text {th }}, 2016$.

Wilde, G. J. 1982. The theory of risk homeostasis: implications for safety and health, Risk Analysis 2(4): 209-225. 